\title{
Senior Citizens' Cultural Activity and Participation in Community Life
}

\author{
Fábia Barbosa de Andrade, Tainara Lôrena dos Santos Ferreira, Dídia de Oliveira Pereira, \\ Íngrid Katianne Marques Araújo, Joymara Railma Gomes de Assunção, \\ Isabelle Christine Fonsêca G. A. Silva, Jéssica Isabelle dos Santos Dutra, \\ Aline de Lima Cabral \\ Faculty of Health Sciences of Trairi (FACISA), Federal University of Rio Grande do Norte (UFRN), Santa Cruz, \\ Brazil \\ Email: fabiabarbosabr@yahoo.com.br, tainara lorena@hotmail.com, didia oliveira@hotmail.com, \\ ingridkati@hotmail.com, railmas@hotmail.com, isabellefonseca1@hotmail.com, jessicabellejp@hotmail.com, \\ enila cabral@hotmail.com
}

Received 1 September 2014; accepted 19 July 2015; published 22 July 2015

Copyright (C) 2015 by authors and Scientific Research Publishing Inc.

This work is licensed under the Creative Commons Attribution International License (CC BY).

http://creativecommons.org/licenses/by/4.0/

(c) (i) Open Access

\begin{abstract}
Objective: This study has the objective to know the cultural activities of the senior citizen and their participation in community life as encouraged by Primary Health Care professionals. Methods: This is a quantitative study that was performed on 130 senior citizens in the city of Santa Cruz, in the Brazil state of Rio Grande do Norte. Results: The participation of senior citizens in groups is very beneficial because it increases their autonomy and self-esteem, socialization, wellbeing and consequently, which leads to a higher quality of life. However, there were some failures in the promotion of healthy aging and the adoption of strategic activities. Conclusions: Based on this observation, it is expected that this study can provide resources for the primary health care professionals to try to stimulate senior citizens by carrying out cultural activities that value and increase their potential, quality of life and self-esteem and, thus, promote active and healthy aging.
\end{abstract}

\section{Keywords}

Quality of Life, Health of the Elderly, Primary Health Care

\section{Introduction}

Aging is a multifactorial process mainly influenced by elements intrinsic to the morpho-physiological changes and elements which depend on the social dynamic and characteristics of each individual. Although the senior 
citizen may be active and considered as someone who has a lot to teach upcoming generations, this process has characterized itself many times through the construction of negative stereotypes which influence how the senior citizen sees their aging process and consequently, makes them feel excluded.

A senior citizen is anyone 60 years of age or older and aging is a dynamic and aging process in which there is morphological, physiological, biochemical and psychological modifications that determine the progressive loss of capacity of the individual to adapt to the environment resulting in greater vulnerability and the prevalence of pathological processes which ended up causing death. It is a phase of life that's full of one's own qualities and values in which transformations occur in the individual's organic structure, immunity, nutrition, functional mechanisms, emotional and intellectual conditions and even communication wise, since there are distinct perceptions among people [1].

Thus, thinking about the meaning of aging is a path to understanding its real meaning. It permits senior citizens to maintain their autonomy and independence, with the understanding of the changes resulting from aging, reflected in old age, as well as enable an improved quality of life related to the senior citizen's health, as the parameter.

Studies show that there are eleven important factors for quality of life in senior citizens: cognitive and emotional function; satisfaction with life and well-being; and the financial independence; social, recreational and sexual function along with the factors related to the physical dimension which contribute to the execution of tasks and maintenance of their independence [1].

The cultural aspects modify the way of analyzing aging and consequently, the way the senior citizen will be in this environment. The possibility of aging successfully depends on several factors like life history, family support and the way each one understands the aging process, among other [2].

The fact is that old age is still unappreciated by society and it limits the senior citizen in regards to the possibilities of change and growth. However, many of these people struggle for respect, dignity, confidence, security and good quality of life with the goal of ensuring the place in the cultural and social environment.

Thus, by considering the senior citizen relatively inactive and dependent on others, society often causes social exclusion, since it does not recognize their activeness in the community. However, it is important to note that the maintenance of paid work, relating with friends at least once a month, watching TV and taking part in hands-on activities are independent factors to protect the senior citizen's disability. Thus, social interaction decreases the probability that they will lose functional capacity early. Therefore, the activities of work and leisure should be valued and encouraged throughout life, especially at older ages, as well as relationships with friends and, especially, the social, cultural, biological, medical factors that can harm or complicate the sustention of these activities by the senior citizens [3].

Society should try to modify concepts, above all, in relation to old age and the aging process. Today, it's desired to comprehend old age, spreading its innovations and probabilities of participating in everyday life [4].

Therefore, it is essential that the senior citizen can age healthily, so that it is put in a social setting, with an active role in their personal and professional lives, guaranteeing its independence and place within society.

Aging is a complex phase of changes in the trajectory of people's lives. It is the phase in which each situation has its own peculiarities responsible for modifying the lifestyle of each person. With this, the ways to reveal the meaning of old age and the aging process for senior citizens will depend on each person's experience, their accommodation and daily confrontations. The impact of aging is contested by the elderly differently since it depends on their personal life story, the availability of emotional support, social networks, personal value system and way of life adopted by each one [3].

Thus, by understanding that aging it is a multifaceted process where measures taken directly influence the quality of life, which may increase their autonomy and independence, while keeping in mind that in addition to living longer, it's fundamental that the senior citizen live well, this study aims to assess activities the cultural support proposed by the Primary Health Care in the older person with respect to attribute cultural com-petence, facilitating the relationship with the community.

\section{Methodology}

This is an exploratory-descriptive study with a quantitative approach that was carried from July to December 2012 in the city of Santa Cruz, located in the Brazilian state Rio Grande do Norte. The interviews were done on a sample set of 130 senior citizens, not probabilistic and convenience, according to the criteria of inclusion and 
exclusion.

This study is a clipping from the research entitled Atenção Primária à Saúde: um estudo de avaliação na perspectiva dos usuários (Primary Health Care: an evaluative study from a user's perspective). The criteria were being a senior citizen with cognitive capacity intact, reside in the selected UBS community and sign an Informed Consent form. The elderly were chosen according to accessibility.

The interviews were conducted by interviewers students the undergraduate in nursing UFRN/FACISA previously trained using the instrument Primary Care Assessment Tool (the PCATool). The interview was conducted on the environment and booked individually, after explaining the research objectives, as well as reading and signing the Informed Consent Form (ICF) by the subjects. The validated version of PCATool consists of forty-five questions (six to access the first con-tact ten continuity five for coordination, fourteen for completeness, six for family counseling and four for community orientation). It notes that the PCATool is an instrument with Likert-type responses, with 1 - 4 interval for each attribute.

The results were inserted and analysed in the Statistical Package for the Social Sciences (SPSS), version 17.0. Calculating the mean, median and standard deviation, variance and chi-square test were performed with significance level values below 0.05 and a confidence interval of $95 \%$.

The study followed all the regulations contained in the National Health Council Resolution 466/2012, regarding studies with human beings. The project was submitted and approved by the Ethics and Research Committee (CEP), of the Federal University of Rio Grande do Norte (UFRN), under number 152/2012.

\section{Results}

This study made a survey to evaluate to assess activities the cultural support proposed by the Primary Health Care in the older person with respect to attribute cultural competence, facilitating the relationship with the community. The sample set was composed of 130 senior citizens, with $29.2 \%(n=38)$ men and $70.8 \%(n=92)$; and the majority lived with the spouse.

The average education level of respondents elderly was 1.58 years of study, median of 0.25 years, standard deviation of 2.07. The average age was 72.85; median 72.00 and a standard deviation of 8.30 , as shown in Table 1. As for the quality of care provided by community health staff $51.5 \%(n=67)$ classified as regular, followed by 38.5\% ( $\mathrm{n}=50)$ good, 5.4\% $(\mathrm{n}=07)$ terrible, 3.8\% $(\mathrm{n}=05)$ bad. Regarding the quality of cultural support provided by staff $43.8 \%(n=57)$ classified as regular, $38.5 \%(n=50)$ good, $13.1 \%(n=17)$ bad, $3.8 \%(n=05)$ terrible.

A significant correlation was perceived in the table above, confirmed by the value $\mathrm{p}=0.003$, which shows that most people assessed as positive the kind of satisfactory service. When questioned about the concern of PHC health professionals with inviting them to participate in the groups looking for a higher quality of life 38.5\% (n $=50)$ of senior citizens never said anything; 32.3\% $(n=42)$ sometimes; $15.4 \%(n=20)$ always said something (Table 2).

In Table 3 there was a significant correlation confirmed by the value $=0.014$. And, in reference to the senior citizens to be invited by the PHC health professionals to participate in discussions in the community and at work $45.4 \%(n=59)$ claimed never to be invited; 23.8\% $(n=31)$ rarely, while $23.8 \%(n=31)$ claimed sometimes.

Table 4 shows its significance by the value $\mathrm{p}=0.001$, and points out that when questioned about the elderly

Table 1. Socio-demographic information of the respondents. Santa Cruz/RN, Brazil.

\begin{tabular}{cccc}
\hline Variables & Mean & Median & Std. deviation \\
\hline Education-years studied & 1.58 & 0.25 & 2.07 \\
Age & 72.85 & 72.00 & 8.30 \\
\hline
\end{tabular}

Table 2. Correlation between classification quality of care to the community and invited to join the group of seniors who seek a better quality of life. Santa Cruz/RN, Brazil.

\begin{tabular}{|c|c|c|c|c|c|c|}
\hline & Never & Sometimes & Always & Rarely & Frequently & p-value \\
\hline Invitation to participate in Senior Citizen groups & $\begin{array}{c}38.5 \% \\
(n=50)\end{array}$ & $\begin{array}{c}32.3 \% \\
(\mathrm{n}=42)\end{array}$ & $\begin{array}{c}15.4 \% \\
(n=20)\end{array}$ & $\begin{array}{c}8.5 \% \\
(n=11)\end{array}$ & $\begin{array}{c}5.4 \% \\
(n=07)\end{array}$ & 0.003 \\
\hline
\end{tabular}


feel responsible for social and cultural development in the health service, $38.5 \%(\mathrm{n}=50)$ stated never; $40.8 \%(\mathrm{n}$ $=53)$ sometimes and $16.2 \%(n=21)$ stated rarely. Regarding health professionals carrying out celebrations that value senior citizens, $30.8 \%(n=40)$ said never; while $29.2 \%(n=38)$ sometimes and $27.7 \%(n=36)$ said always, which indicates a significant result for the obtained value $\mathrm{p}=0.001$ (Table 5).

A significant correlation (Table 6) was reached, in relation to incentives by PHC health professionals for the cultural support described in Table 6 with the value $\mathrm{p}=0.002$ being confirmed. In this way, $43.8 \%(n=57)$ classified as regular; $38.5 \%(n=50)$ good; while $13.1 \%(n=17)$ classified as bad.

\section{Discussion}

It is known that senior citizens in peer groups benefit greatly because it expands their autonomy and self-esteem, improves their living and well-being, thus a higher quality of life. The average age was 72.85 ; median 72.00 and a standard deviation of 8.30, as shown in Table 1. Group living provides well-being and emotional balance, allows the exchange of experiences, as well as help human beings to face old age in a more relaxed and healthy way [5]. The meanings that senior citizens attribute to themselves at the time of aging, as well as those attributed by others, makes all the difference because they contribute with the evaluation and personal investments of this clientele [6].

However, observed in Table 2 through higher percentages of "never" and "sometimes", the lack of support on the part of PHC health professionals. Percebe-se assim, que os profissionais de saúde precisam estimular práticas de promoção do envelhecimento saudável, observando todos os fatores que venham a contribuir uma melhor qualidade de vida. According to the authors [3] supporting knowledge about the elderly group should be part of health care, because it helps their integration in social interaction, thus protecting the elderly individual's functional loss and consequently age successfully. These data show the need for the municipal, state and federal governments to develop operational plans that are integrated into society as a way of rescuing new forms of quality of life for the elderly.

The way in which the elder faces the aging process is influenced from the way the other sees this process. Therefore, it is important to (re)define aging in society, aiming for people to look at senior citizens in a positive

Table 3. Correlation between classification quality the cultural support and invitations from PHC health professions for participation in discussions in the community and at work. Santa Cruz/RN, Brazil.

\begin{tabular}{|c|c|c|c|c|c|c|}
\hline & Never & Sometimes & Always & Rarely & Frequently & p-value \\
\hline Invitations for participation in discussions in the community and at work & $\begin{array}{c}45.4 \% \\
(n=59)\end{array}$ & $\begin{array}{c}23.8 \% \\
(n=31)\end{array}$ & $\begin{array}{c}2.3 \% \\
(n=03)\end{array}$ & $\begin{array}{c}23.8 \% \\
(n=31)\end{array}$ & $\begin{array}{c}4.6 \% \\
(n=06)\end{array}$ & 0.014 \\
\hline
\end{tabular}

Table 4. Correlation between quality classification of cultural support and the elderly feel responsible for social and cultural development in the health service. Santa Cruz/RN, Brazil.

\begin{tabular}{|c|c|c|c|c|c|c|}
\hline & Never & Sometimes & s Always & Rarely & Frequently & p-value \\
\hline Elderly feel responsible for social and cultural development in the health service & $\begin{array}{c}38.5 \% \\
(n=50)\end{array}$ & $\begin{array}{c}40.8 \% \\
(n=53)\end{array}$ & $\begin{array}{c}3.8 \% \\
(n=05)\end{array}$ & $\begin{array}{c}16.2 \% \\
(n=21)\end{array}$ & $\begin{array}{c}0.8 \% \\
(n=01)\end{array}$ & 0.001 \\
\hline
\end{tabular}

Table 5. Correlation between quality classification of cultural support and PHC health professionals carried out celebrations that value senior citizens. Santa Cruz/RN, Brasil.

\begin{tabular}{lcccccc}
\hline & Never & Sometimes & Always & Rarely & Frequently & p-value \\
\hline Celebrations that value senior citizens & $\begin{array}{c}30.8 \% \\
(\mathrm{n}=40)\end{array}$ & $\begin{array}{c}29.2 \% \\
(\mathrm{n}=38)\end{array}$ & $\begin{array}{c}27.7 \% \\
(\mathrm{n}=36)\end{array}$ & $\begin{array}{c}10.0 \% \\
(\mathrm{n}=13)\end{array}$ & $\begin{array}{c}2.3 \% \\
(\mathrm{n}=03)\end{array}$ & \begin{tabular}{c}
0.001 \\
\hline
\end{tabular}
\end{tabular}

Table 6. Correlation between classification quality of care to the community and quality classification of cultural support. Santa Cruz/RN, Brazil.

\begin{tabular}{ccccccc}
\hline & Regular & Good & Bad & Terrible & Excellent & p-value \\
\hline Incentives for cultural support & $\begin{array}{c}43.8 \% \\
(\mathrm{n}=57)\end{array}$ & $\begin{array}{c}38.5 \% \\
(\mathrm{n}=50)\end{array}$ & $\begin{array}{c}13.1 \% \\
(\mathrm{n}=17)\end{array}$ & $\begin{array}{c}3.8 \% \\
(\mathrm{n}=05)\end{array}$ & $\begin{array}{c}0.8 \% \\
(\mathrm{n}=01)\end{array}$ & 0.002 \\
\hline
\end{tabular}


way and thus contributing so that they feel and see themselves as active people, and, and that they still have important experience to pass on to the community. As shown in Table 3, as regards the elderly receive invitations to participate in discussions in the community and at work, it was observed that most states "never" followed by "rarely" and "sometimes" this finding leads to discussion, participation in society and the formation negative stereotypes of the elderly.

Considering the data in Table 4 and Table 5, it was found from "never" and "sometimes" the need of the healthcare team to promote self-care practices in view of the importance for healthy and active aging. The value of a senior citizen by way of cultural activities and leisure realized by health professionals should be carried out in such a way that stimulates their functional capacity, self-esteem and independence for daily activities, in addition to their work ability. The health professional needs to have a holistic outlook for this population, not just observe the appearance of chronic diseases, but also aim for a higher quality of life and the (re)construction of the meanings of this phase of life.

To improve the quality of life of the senior citizen, it is necessary to include regular physical activity as a means of prevention and possibly delaying the onset of chronic diseases. We must also help them psychologically, just as in the adaptation of new motor conditions with the aim of improving functional capacity and prevent mental aging. Thus, it was noticed that seniors who engage in regular exercise have better overall health than those do not, and that factor has a great impact whose usefulness should be encouraged assistance in Primary Health care (PHC) so that senior citizens have healthy lifestyles [7].

Some successful experiments have been performed in groups of living of the elderly, such as recreational activities, educational practices with health issues, moments of physical activity, among others, but still it is necessary to enhance these experiences in all social realities.

The care offered by PHC is focused on healing and is only directed at user complaints. Despite the health professionals knowing the importance of activities that value the beliefs and values of the aging population, they're still limited in the realization of an educational process that enables an offer for a higher quality of life. Thus, it's necessary to research the aging taking into consideration their socio-economic situation and culture, religion, available activities, regionality and especially the individuality of each one in regards to their own aging [2].

Even though the conditions of senior citizens' health have much in common with the rest of the population, it is important to evaluate the necessities of the state of health of local senior citizens with the purpose of providing assistance services and programs that promote healthy aging in accordance with the population studied. And that this evaluation includes several aspects like the body's state of health, along with the mental and social parts too [7].

It may be mentioned in this context the inclusion of the practice of self-esteem that must be provided in government plans and, therefore, integral health practices should be included in the daily population is aging with a view to the quality of life of this population.

The data in Table 6 reveals the necessity for cultural support. In this way, it's necessary for the health team to conduct a survey about the difficulties that preclude the development of activities that promote cultural support, as well as the real necessities and expectations of the aging population. Therefore, health professional should be participative, critical and sensitive, capable of establishing a network between the health establishments and community, looking to extend care for the aging [1].

However, it was perceived that the incentive, on the PHC professionals' part, for cultural support needs to be strengthened due to the classification in the users' perception as being "regular" most of the time. This study reveals the importance in the implementation of primary health network well located and quality services to elderly health, which must be ever closer to the elderly to respect the right of access to health and wholeness, further comprising the right to health that old people have in the community. Brazil has increasingly primacy for quality care for the elderly population, it has allowed the creation of public policies for healthy aging.

\section{Conclusions}

In face of what was exposed, from the user's perception, it can be noted that primary health professionals still need to strengthen activities that value senior citizens and stimulate their participation in the community in such a way that improves their quality of life, self-esteem and cognitive functions. The failures can be observed where the answers are "never" and "sometimes", when questioned about orientation and activities designed for 
senior citizens.

It is important that health professionals realize the full mode elderly in their social, biological and cultural dimensions, promoting participation in community groups and guiding this stage of life the transformation of life.

The stimulation on the part of the Primary Health Care professionals with the practice of cultural activities greatly influences, not only the biological and cognitive functions, but also inclusion of the senior citizen in society given that it (re)establishes the social representations of the senior citizens and enhances the perception of old age. However, one should promote social participation that favors the creation and maintenance of groups dedicated to this audience, and even improves senior citizen relations, since it undoes the negative stereotypes that were created in society and presents the senior citizen as a wise elder seen as a source of pride and example for the community, being synonymous with a complete and quality life. On the other hand, it is worth remembering that this study has limitations due to the nature of the study clientele.

Lastly, it is hoped that this study can provide the tools that sensitize primary health care professionals to try stimulating the senior citizen by organizing activities that value and increase their potential, quality of life and self-esteem and thus, promote active and healthy aging.

\section{References}

[1] Tavares, D.M.S., Dias, F.A. and Munari, D.B. (2012) Quality of Life of the Elderly and Participation in Group Educational Activities. Acta Paul Enferm, 25, 601-606. http://www.scielo.br/pdf/ape/v25n4/en_aop2012.pdf

[2] Guerra, A.C.L.C. and Caldas, C.P. (2010) Difficulties and Rewards on Aging: The Elderly’s Self Perception. Ciência \& Saúde Coletiva, 15. http://www.scielosp.org/pdf/csc/v15n6/a31v15n6.pdf

[3] D’orsi, E., Xavier, A.J. and Ramos, L.R. (2011) Work, Social Support and Leisure Protect the Elderly from Functional Loss: Epidoso Study. Revista de Saúde Pública, 45, 685-692. http://www.scielo.br/scielo.php?script = sci_arttext\&pid = S0034-89102011000400007\&lng = en\&nrm = iso

[4] Freitas, M.C., Queiroz, T.A. and Sousa, J.A.V. (2010) The Meaning of Old Age and the Aging Experience of in the Elderly. Rev EsC Enferm USP, 44. http://www.scielo.br/pdf/reeusp/v44n2/en_24.pdf

[5] Celich, K.L.S. and Spadari, G. (2008) Health and Lifestyle: Conditions for Healthy Aging. Cogitare Enferm, 13, 252-260. http://ojs.c3sl.ufpr.br/ojs/index.php/cogitare/article/viewFile/12497/8559

[6] Hein, M.A. and Aragaki, S.S. (2012) Health and Ageing: A Study of Brazilian Masters Dissertations (2000-2009). Ciência \& Saúde Coletiva, 17.

[7] Chao, J., Li, Y., Xu, H., Yu, Q., Wanga, Y. and Liu, P. (2013) Health Status and Associated Factors among the Community-Dwelling Elderly in China. Archives of Gerontology and Geriatrics, 56, 199-204. http://dx.doi.org/10.1016/j.archger.2012.10.001 